\title{
Organizational Constraints to Realizing Business Value from Service Oriented Architectures: An Empirical Study of Financial Service Institutions
}

\author{
Haresh Luthria and Fethi Rabhi \\ Information Systems, Technology \& Management, The Australian School of Business \\ The University of New South Wales, Sydney, Australia \\ \{h.luthria, f.rabhi\}@unsw.edu.au
}

\begin{abstract}
Service-oriented architectures (SOAs) are gaining popularity as an approach to provide flexibility and agility, not just in systems development but also in business process management. Studies of the practical business impacts of SOA are crucial as the number of SOA implementations grows, and are required for a better critical understanding of this popular architectural concept that is being rapidly adopted by industry organizations. Although there is a significant amount of ongoing research related to technology implementations of SOAs, there is a paucity of research literature on the factors affecting the adoption of service-oriented computing and the realization of business value in practice. This paper empirically examines the adoption of service-oriented computing (SOC) as an enterprise strategy across fifteen firms, and discusses the organizational constraints that influence the enterprise adoption and implementation of SOA. In doing so, this paper fills a crucial gap in the academic literature about the practical use of SOA as an enterprise strategy for agility, and lays the groundwork for future work on SOA alignment with organizational strategy. The paper also provides practitioners with guidelines for the successful implementation of SOA to achieve business value.
\end{abstract}

Keywords: Service Oriented, SOA, SOC, Business Value, Organizational Constraints, Technology Adoption, Technology Diffusion.

\section{Introduction}

In response to dynamically changing market conditions, financial institutions are increasingly looking for avenues of organizational agility [2]. By virtue of being the underlying enabler of the core business processes, information technology is very critical to achieving this agility [13]. Technology infrastructures built on service oriented computing principles appear to facilitate business process and, subsequently, organizational agility [17]. The paradigm of Service Oriented Computing (SOC) views whole business functions as modular, standards-based software services. The associated Service Oriented Architecture (SOA) establishes a defined relationship between such services offering discrete business functions and the consumers of these services, independently of the underlying technology implementation [23]. 
There is a great deal of enthusiasm in the industry about this concept but the adoption of SOA by end-user organizations is still in a relatively early stage [24]. Therefore, there is a scarcity of critical research addressing the ability of organizations to realize business value from the adoption of SOA. From a pragmatic perspective, there is widespread recognition of the fact that various organizational issues need to be addressed for the successful implementation of any information technology [14]. What is needed beyond the current research on the technology implementations of SOA, is a focus on the study of the real-world adoption of SOA across the enterprise and the factors that aid or impede such adoptions. This understanding becomes even more critical in the context of financial services institutions since the strategic impact of information technology is very high for financial institutions, and the industry sector is at the leading edge of the adoption curve for innovative technology solutions [20].

This paper empirically examines the use of SOA across fifteen firms - a mix of banks, insurance firms, and service providers - and as part of a broader study, specifically investigates the best practices promoted by service providers, and the organizational constraints and challenges experienced by firms considering the enterprise-wide implementation of SOA. The results provide insights into the factors that impact the real-world adoption of SOA, thus filling a crucial gap in academic literature. The paper also aligns organizational constraints with advocated best practices, thus providing practitioners with a guide to maximizing business value from their SOA implementations.

Section 2 describes the empirical study of SOA adoption across fifteen firms and the data collection and analysis processes used. Section 3 describes the observed trends in the results of the use of SOA across these firms. Section 4 distils the results of the empirical study by comparing suggested best practices for SOA adoption with the organizational challenges faced on the ground. Finally, Section 5 summarizes the research contribution and the business impact of the paper.

\section{The Empirical Study - Data Collection and Analysis}

A case study approach was chosen as the research methodology to study the alignment and adoption of SOA across the enterprise because, according to Benbasat et al [3], case studies are "well-suited to capturing the knowledge of practitioners and developing theories from it".

Fifteen firms - a mix of both financial service institutions in the banking and insurance sectors, and software service providers that had a significant number of clients in the financial services industry - were approached to understand their position on SOA. Most of these firms were chosen based on their involvement in industry conferences on SOA which was an indication of their interest in adopting SOA. A few, however, were chosen on an opportunistic basis leveraging a network of contacts. Table 1 describes the industry sector and profile of the firms interviewed as well as the designation of the interviewees. 
Table 1. Summary of Firms Interviewed

\begin{tabular}{|c|c|c|c|}
\hline Firm & Sector & Interviewee & Profile \\
\hline 1 & Bank & Head of Strategy & Large Australasian private bank \\
\hline 2 & Bank & $\begin{array}{l}\text { Business development ex- } \\
\text { ecutive; } \\
\text { Technical Architect }\end{array}$ & Large U.K. based private bank \\
\hline 3 & Bank & $\begin{array}{l}\text { Business development ex- } \\
\text { ecutive }\end{array}$ & Large Europe based private bank \\
\hline 4 & Bank & $\mathrm{CIO}$ & India's second largest private bank \\
\hline 5 & Bank & Enterprise Architect & Mid-sized Australasian public sector bank \\
\hline 6 & Bank & Enterprise Architect & Large Australasian private bank \\
\hline 7 & Insurance & $\begin{array}{l}2 \times \text { Technology manager / } \\
\text { Architect }\end{array}$ & Mid-sized Indian private general insurance firm \\
\hline 8 & Insurance & СТO & Large Indian public sector general insurance firm \\
\hline 9 & Insurance & $\mathrm{CIO}$ & Large Australasian private insurance firm \\
\hline 10 & Insurance & Enterprise Architect & Large Australasian public sector insurance firm \\
\hline 11 & $\begin{array}{c}\text { Product \& } \\
\text { Services }\end{array}$ & $\begin{array}{l}\text { CTO; VP of Strategic Ac- } \\
\text { counts }\end{array}$ & Small India-based ERP solutions firm \\
\hline 12 & $\begin{array}{c}\text { Product \& } \\
\text { Services }\end{array}$ & Technical architect & Large European ERP solutions firm \\
\hline 13 & $\begin{array}{l}\text { Product \& } \\
\text { Services }\end{array}$ & Technical architect & Large U.S. based software and services firm \\
\hline 14 & Services & $\begin{array}{l}2 \times \text { Technical architect; } \\
\text { Product manager }\end{array}$ & $\begin{array}{l}\text { Large India-based software services and consult- } \\
\text { ing firm }\end{array}$ \\
\hline 15 & Services & Principal & Large multi-national consulting firm \\
\hline
\end{tabular}

Semi-structured interviews were conducted with business managers, enterprise architects, and CIOs/CTOs of 13 (thirteen) of these firms. A broad set of questions addressing specific areas of discussion (implementation details, challenges and concerns, benefits realized, lessons learned) was used to guide the interviews. Wherever possible, the interview data was augmented by documents provided by the interviewees. Each of the individual interviews lasted an hour with the exception of the interview with Firm 5, which lasted 30 minutes.

Communications with Firms 10 and 15 were limited to electronic communication. Firm 10 indicated that their firm did not have an explicit SOA strategy, but they were pursuing SOA practices at a technical level by "following reasonable SOA practices in terms of trying to keep things abstracted through the use of messaging middleware and a messaging portal”. Firm 15 was able to supply documents describing its SOA strategy at the business and technical levels, and provide specifics of a case study of a 
large financial services firm. Firms 10 and 15 are both included in the analysis not as primary data but more as an emphasis to the findings from the data gathered in the interviews with the other firms.

Fourteen of the firms interviewed were in various stages of implementing SOA, most of them already having migrated targeted business functions to a service based deployment. The firms were able to provide some insight into the anticipated and observed benefits of the migration to a service-oriented approach. Firm 6 did not have an SOA strategy and had tried unsuccessfully to migrate to a service based infrastructure. The interview provided a valuable insight into the challenges of building a business case for SOA adoption. The product and software service providers (Firms 11-15) were able to provide an insight not only into the business drivers for their product offerings but also their perception of the business drivers for their clients.

Transcriptions of the individual interview data were analyzed using a two-pass method. The first pass of the analysis used thematic coding to identify broad categories of organizational issues. The second pass of analysis was performed using axial coding and major factors were identified using meta-codes. The meta-codes were then used to identify similar patterns across the data from the multiple firms interviewed. The following section details the results of the data analysis identifying the major themes of suggested best practices and organizational factors affecting the implementation, and the cross-firm patterns observed within these themes.

\section{The Empirical Study - Results}

Despite the many potential benefits of information technology innovations, organizations have generally found it very difficult to achieve the promised benefits [43], and the successful implementation of SOA appears to have its fair share of challenges. It is interesting to note that even in the limited scholarly work on the use of SOA in the business domain, an empirical study of two European banks indicated that the "[business] service concept was difficult to define in practice" [1].

We were able to get a significant understanding of the constraints impacting the organizational adoption of SOA running the gamut from funding at the corporate level to performance challenges at the implementation level. These constraints were compared with the best practices suggested by service providers to get an understanding of how firms were actually implementing these practices. The best practices are discussed in Section 3.1, and the constraints that impact each best practice are detailed in the following sections (Sections $3.2-3.8$ ) and summarized in Table 2 at the end of this section.

\subsection{Best Practices Suggested by Service Providers}

Service providers, Firms 11-15, were able to provide us an insight into what lessons they thought they had learned from their experiences, and more importantly, mistakes, and what they would consider best practices for a successful enterprise SOA implementation. These experiences were collectively analyzed and distilled by thematic 
categorization into a set of proposed best-practices for successful enterprise-level SOA adoption. These best practices are summarized below:

1. Get commitment at the board level.

2. Manage expectations - Invest in SOA for the long term.

3. Align the entire organization along the SOA strategy.

4. Change the mindset of people - SOA is not about technology, it is about transforming the business process.

5. Governance is critical.

6. Focus on training.

7. Leverage existing resources.

SOA is all pervasive, according to the Development Architect of Firm 12, and you need to get commitment at the board level if the adoption of SOA at the enterprise level is to be successful. Along with commitment at the board level, the expectations of people across the organization need to be managed. There needs to be an acknowledgement that the governance and training associated with service orientation could possible end up costing much more than the development of the services.

SOA should be viewed as an evolving process and not a silver bullet. There needs to be a clear understanding at the senior management level that SOA is a long-term investment in time and resources, according to Firms 12 and 14. Success is more probable when starting out with a small project to show business value before rolling out service orientation on a larger scale, according to Firm 15.

The Development Architect of Firm 12 indicated that the commitment at the board level needs to permeate the organization to ensure that the entire organization is aligned with the SOA strategy. Organizations need to get "everyone on the same page on the SOA strategy". The theme underlining this enterprise wide alignment needs to be that SOA is not about the technology, it is "a way of thinking". This requires that people's mindset needed to be changed to ensure that the focus of SOA adoption should be on transforming business processes (Firms 13 and 15).

A majority of the effort in implementing SOA appears to be implementing an appropriate governance framework in place (Firm 12), and appropriate training (Firms 12-14). Business people need to be trained in Business Process Modeling and technical people in the business aspects of services in addition to the appropriate technical training on the use of tools (Firm 14). Firm 15 indicated the need to be cognizant of when SOA may not be appropriate. Firms 12, 13, and 15 emphasized that both business and technology teams need to understand that SOA is not about creating new functionality but leverage existing resources more effectively.

These empirically gleaned best practices, it may be argued, are fairly sound generic software adoption guidelines and match up with what existing analytical SOA-related literature suggests. So what does this really mean in the real world? The input from individual firms as well as service providers' experiences with client implementations was analyzed independent of suggested practices to better understand how the SOA implementations actually fared with the rollout of SOA across the enterprise. The following sections describe this analysis in detail. 


\subsection{Get Commitment at the Board Level}

At the organizational level, there appears to be no direct business case for SOA, as indicated by Firms 1, 4, 6, 7, 9, and 10. The general approach to SOA was captured pithily by the CIO of Firm 9, who said "Using SOA increases IT value...[but] we are implementing SOA by stealth. We have no business case for SOA."

The data also suggests that at the very high business level or customer facing level, the enterprise offerings are treated as service offerings by business units of most firms, including Firms 2, 3, 4, 8, and 9, with the business executive at Firm 3 using the term services interchangeably with applications. Business units view their offerings as a set of services, according to Firm 3, and so cannot understand why the IT teams are not already service oriented. At a business process level, however, there is no service oriented thinking and it is left to the technology teams to push service thinking up from the technology infrastructure implementing the business processes.

\subsection{Manage Expectations - Invest in SOA for the Long Term}

Funding was an issue for Firms 2, 6, and 9, since SOA needs a significant investment and business users are not willing to spend money for something intangible that may only be achieved in a few years time. The move to SOA requires significant investment in time and resources for longer-term benefits, but the technology teams in Firms 2, 4, and 9 were faced with the difficulty of defining what the return-oninvestment (ROI) would be for SOA. According to the VP of Technology of Firm 2, "business deadlines do not change. How do you convince business units to spend money and time? Business units want it now. They don't want to spend money for something three years down the road. We had to couch [the SOA implementation] in some other terms like infrastructure updates".

From an implementation perspective, model based development was critical to the success of SOA implementations according to the service providers we spoke with, specifically Firms 12 and 13. However, there are no mature tools to either directly orchestrate business services to create an application or to translate the business process models to technical services as an intermediate step. Firm 12 uses models to elicit business requirements, but manually maps them to technical infrastructure requirements. According to Firm 14, which had unsuccessfully tried model based development on client projects, "Changes in the business process are hard to reflect in technical services. So [you end up with] two flows - business process modeling and technical process modeling. The mapping is a manual effort. Ideally we would have liked to model business processes, to technical services, to implementation. But changes cycling back cause problems because [the available] tools don't support this". The technical architect at Firm 2, relating a similar experience regarding their attempted BPM adoption effort said "BPEL has inherent problems. The [software] vendor says it all works - the model translates to the system. The reality is that the business unit can model its process and simulate BPR scenarios, but once the development is done, if you implement any technical change then things fall apart. BPEL has a round trip problem as a language in supporting this real-world development process. So now we define a business process model, and then manually translate it to Business Requirements and Use Cases. The business analyst draws up the business 
process. The techie looks at the diagram and imports into a BPM tool. Modifications even at the process level were a problem. The processes were modeled mostly on paper - and then translated to BPM the tool. It served as documentation for future maintenance but using the models is a challenge."

Although major software vendors have rallied around the concept of serviceoriented computing [24], there still is no single unified view of the basic communications standards involved across the board [15, 19]. So despite the integration of systems, both internal and external, being a business driver for the adoption of SOA, integration across domains continues to be a challenge that goes beyond service thinking. While executives at Firms 1 and 4 were skeptical of the promise of plug-andplay, Firms 2 and 6 were experiencing problems integrating external systems because of differing standards. Firm 6, in facing the integration effort after an acquisition, found that even adopting a standard like IFX ${ }^{1}$ still did not help since the contextual or semantic relevance of the data varied across the two systems being integrated. Service providers like Firms 12 and 14 also indicated that the kinds of integrations they were seeing with clients were all one-off or custom integrations. This makes it harder to sell SOA as a plug-and-play infrastructure.

Standards notwithstanding, by virtue of crossing administrative domains with potential loss of visibility and control, the new cross-organizational business models put an increased emphasis on non-functional business requirements (generally referred to as service quality attributes) such as performance, reliability, transactional integrity, and security [21, 23, 28, 29]. Additionally, with the increasing number of interfaces in a typical inter- and intra-enterprise service-oriented implementation, addressing these systemic issues in an environment of multiple administrative domains, straightforward in theory, becomes a complex problem in practice spanning technical and business arenas $[19,26]$. In practice, many of the firms we spoke with were struggling with the same issues, security and performance, being of the highest concern. Firm 4 found that security could grow to be a challenge not just across external domains because, according to the CIO, a "loose confederation of services creates access and security issues", but also across internal domains. Reuse of services by different users or higher-order services could potentially compromise security as well by changing the context in which the service is used. While Firms 2, 4, 5, 7, and 11 had experienced issues with performance of services because of fine grained services across networks, Firm 14 was grappling with problems of maintaining transactional integrity across services. What was interesting was that all of these issues were approached from a perspective of granularity, with the firms eschewing too fine grained services for performance, security, and transactional integrity, resulting in a trade-off between granularity and service quality attributes.

The use of services also involves a trade-off between granularity and the potential for reuse according to Firms 4, 5, 7, 9, and 11, since the coarser the service, the less the chance to reuse the service in different business contexts or domains. Firm 5, which appeared to have a significant and relatively successful implementation of service-oriented systems across the enterprise compared to the other firms we interviewed, was strongly concerned about the proliferation of services due to the lack of reuse. Firm 7 initiated a service-oriented infrastructure project to address the business

\footnotetext{
${ }^{1} \mathrm{http}: / /$ www.ifxforum.org
} 
requirement for a consistent user experience ("360 degree view of [the] customer") across their three main applications dealing with health insurance, travel insurance, and automobile insurance. The major thrust of this project, called Unified Customer View, was viewed as "a de-duplication effort across all the three systems". Each system had its own web service to retrieve customer data from a back-end transactional systems/applications. So the data had to be retrieved from all three systems and merged to get a complete picture. This removal of redundancy worked well for consistency in user experience, but caused a performance bottleneck since it was a single service addressing queries from three distinct customer bases. As a compromise, the functionality was then split across the single new service and the three older application specific services. Basic customer details were managed via the higher level service and the individual services were invoked only if further customer details were required.

\subsection{Align the Organization Around the SOA Strategy}

One of the biggest challenges in SOA adoption is understanding which business functions can actually be viewed as business services, and how this set of granular services can be used to create a service framework [9]. The business units of Firms 2, 6, 7, 9, and 10 did not understand SOA and were more focused, understandably, on business requirements being met with "consistency, reliability, and uptime". The VP of Engineering for Firm 2 found that the organizational challenge was clearly articulating to the business what SOA could help achieve. "The big problem in my personal opinion is that if something is so great and you cannot explain it - is it really do-able? Vendors say it is a silver bullet but cannot explain SOA in the same way to business owners, techies, and others across organization. People are trying very hard to define SOA, both vendors and end-users, rather than addressing business problems and realizing business value. You need to sell it to fund it and so people are getting lost in defining SOA".

At the technical infrastructure level, the technology teams are actively adopting service-oriented practices for the most part independently of the business units.

\subsection{Change the Mindset from Technology to a Business Process Focus}

Despite the service mind-set of the business units, business process modeling as a strategy was not adopted by the business units as evidenced by Firms 2 and 6 . The translation of the business service requirements to a set of technical services and flows is done by the technology teams using a variety of modeling techniques. In most firms, according to Firms 2, 5, 6, and 12-14, the business services are modeled by the technology teams or representatives of the technology teams, and if needed manually mapped to the technical service architecture. This is consistent with the one other empirical study of the adoption of SOA [1] which found that business processes are not included in the service definitions, which tend to be technical service implementations of the business process flow. 


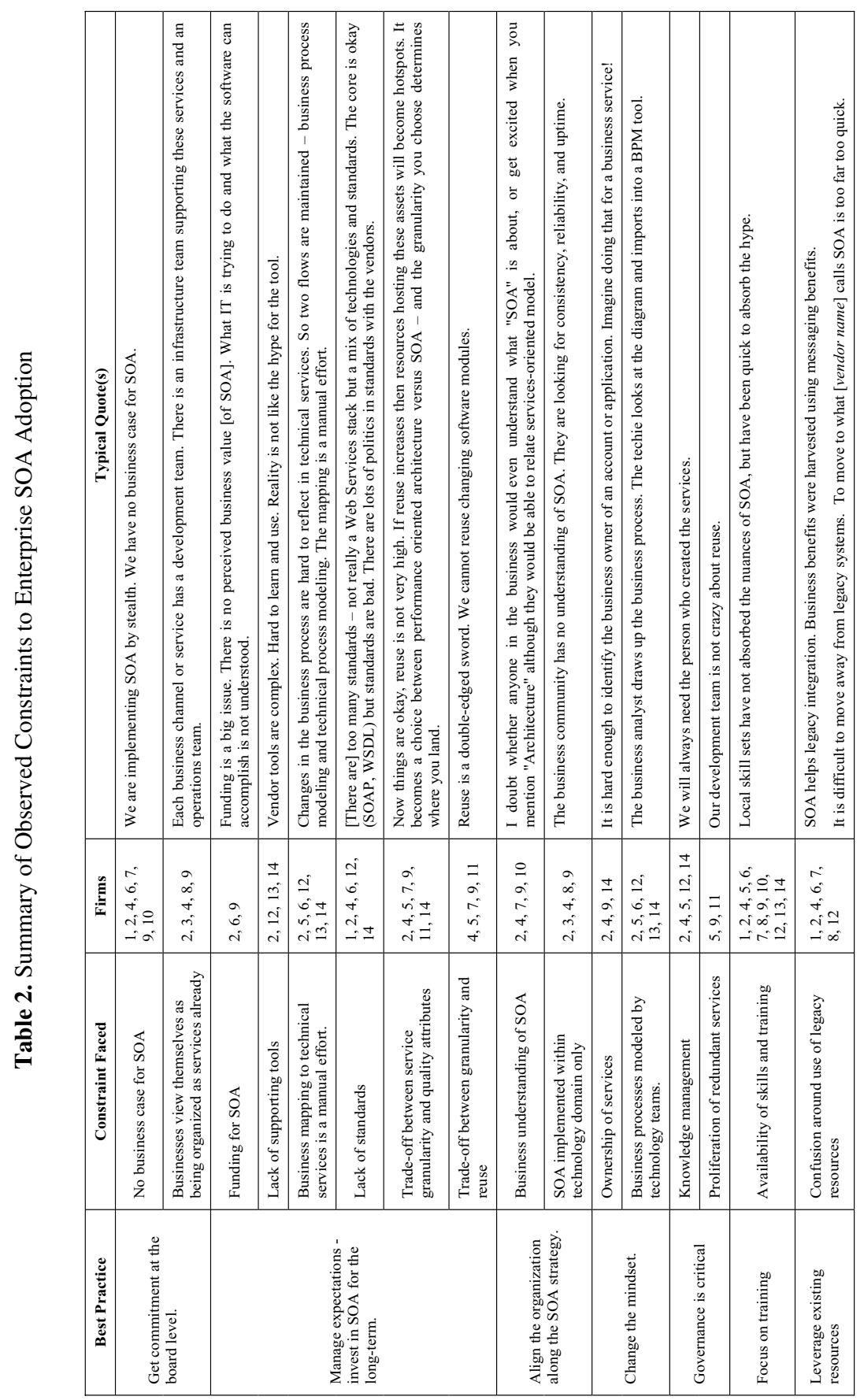


An added potential complication was identified by Firm 14 which found that "breaking application into services causes ownership issues". If a service is created for a business unit and can be used by other units, there is considerable debate of how the service needs to be maintained going forward. Will the business unit that created the service (or the business need for the service), own the service or should the common IT infrastructure team own it? If the needs of a specific user changes should the infrastructure team change the common service or customize another incarnation of the service? Such issues were echoed by the CIOs of both Firm 4 and Firm 9, and the VP of Technology for Firm 2. According to the CIO of Firm 4, identifying business ownership is critical and needed for compliance to industry regulations. "It is hard enough to identify the business owner of an account or application. Imagine doing that for a business service!"

\subsection{Governance is Critical}

The focus of service governance appears to be on knowledge management achieved by "extensive documentation", less on which functions need to be converted to services and more on how the services were going to be created and maintained (Firm 12). The IP related to services - i.e., the knowledge of how the services work and what the inter-dependencies are - was "primarily person-based" and managed via documentation, and this knowledge management of service function and impact was identified as a big concern (Firms 2, 4, 5, 12, and 14).

A critical part of governance is vetting the creation of services to encourage reuse. In practice, however, governance committees are not looking at whether a service needs to be developed but how it will be developed. This lack of reuse results in a glut of redundant services, according to Firm 5, that causes versioning and integrity issues. Firm 9 indicated that service reuse does not work for them for a couple of reasons. The first of these reasons was that some non-critical services had been reused in the past in mission critical applications causing service downtime, and hence dissatisfied customers, when the non-critical services were taken offline for maintenance. The second reason was that the developers preferred to develop something on their own rather than take the time to learn about an existing service and its interdependencies. This was attributed to potential clashes in levels of criticality, pressures of business delivery, and sheer developer propriety. In the CIO's words, "The concern is the speed of reaction to business requirement limits the use of SOA we would like to. We have no vision of reuse. Given the need to react quickly we are concentrating only on rebuilding for use."

\subsection{Focus on Training}

The dependency on individual people for their implicit knowledge was also tied to a concern about availability of the right skills and training. In dealing with business units and strategic partners of businesses, general SOA awareness training and the move to a service mindset was critical, according to Firms 4 and 12. According to Firm 12, $90 \%$ of the effort in implementing SOA is on governance and process engineering, so technical people are not too keen on implementing SOA at an enterprise level. Training business people in using business process modeling tools, was also 
found to be a challenge, according to Firm 2, and so the responsibility of process modeling falls on the technology teams. This requires technical staff to have the requisite "implementation and practical skills". This requires appropriate training for technical people on the business aspect of services and the appropriate technical training on the use of tools. Even at a purely technical level, the sheer complexity of the vendor tools available for the development and management of services required extensive training according to Firm 2, which had unsuccessfully attempted to roll out business process modeling across the enterprise six years earlier. Thus, adopting a service mindset and grooming service-savvy talent on both the business and technical sides was a big concern universally for Firms 1, 2, 4-10, and 12-14.

\subsection{Leverage Existing Resources}

Our cross-firm data also appeared to highlight a lack of understanding of how legacy systems could be leveraged in a service-oriented environment. Firms 4 and 12 strongly advocated finding ways to expose existing legacy resources as services instead of building new functionality. Firm 12 was able to cite the example of a client bank that had taken three years to build a new service based loan system and "scrapped its old loan system...[that] had been in use for 12 years". The lesson learned was that key business functions provided by the existing and proven legacy system should have been exposed as services over time one by one, thus providing a safer and less expensive migration path to a service-oriented infrastructure. Firm 14 also indicated that many firms were attempting to leverage their legacy systems by replacing their Enterprise Application Integration (EAI) frameworks by an Enterprise Service Bus (ESB) and plugging legacy systems into the ESB with service wrappers. Firm 2 was grappling with how to use legacy assets - assessing ways to do this ranging from lightweight approaches like wrappers to attempting to create a full-blown service component architecture which would result in a more complex implementation. Firm 7 was converting its legacy base iteratively to Web Services while Firm 6 could not move away from its legacy systems because the abstraction was complex. Across the firms interviewed, there appeared to be no clear or generally accepted way to leverage proven legacy systems.

\section{Related Work}

There are a few existing studies that empirically investigate the real-world implementations of SOA. Among the studies that look at organizational impacts, two vendorsponsored studies provide insights from client engagements. The first one by Fricko [10], identifies the importance of addressing the organizational culture, specifically with respect to business and technology team interaction, and reuse in the context of a specific IBM project. The second study by Bieberstein et al [4] prescribes a spectrum of guidelines from organizational structure to technology architecture based on the vendors solutions.

From an adoption perspective, Yoon and Carter [30] use publicly available secondary data to study the diffusion of SOA in organizations, while Ciganek et al [7, 8], in 
a study more closely related to the issues being considered in this paper, examine the challenges of adopting Web services across four financial service firms.

The main focus of most other studies is on the value of SOA as an integration strategy. Baskerville et al [1] focus on the strategic benefits achieved from implementing SOA through the lens of the four architectural challenges faced by banks internal application integration, integration with partners, integration in the context of mergers and acquisitions (M\&As), and agile development. The use of SOA as an integration framework in the context of M\&As is also examined by Henningsson et al [12]. The study reviews five companies across industry sectors, and concludes that SOA can be used to effectively integrate disparate systems. Another study by Legner and Heutshi [16] also examines the use of SOA as an integration mechanism in four firms across industry sectors. While the main thrust of the results is the design of SOA for effective systems integration, a by-product of the analysis is a suggested set of three major activities for SOA adoption - (i) introduction of new organizational roles and processes for governance, (ii) creation of architectural guidelines, and (iii) the use of SOA for infrastructure projects.

\section{Contribution and Business Impact}

Research in the area of information technology diffusion indicates that the successful adoption of new technology requires organizations to take an integrated approach to organizational and technical changes introduced by the technology [19]. The technical aspects of SOA appear to have appropriate research efforts and guidelines [23], but there is a lack of similar structure for the examination of the pragmatic impacts of the adoption of SOA. There is a growing understanding of the organizational processes and characteristics that influence the adoption and implementation of technology [5, 14], but there is little understanding of how these organizational constraints may impact the organizational adoption of SOA [18].

Our study adds to current knowledge by reviewing organization-wide challenges to SOA adoption across multiple firms with a fairly broad representation within the financial services industry - banks and insurance firms, which researchers have identified as having high dependence on technology $[13,20]$ - and service providers with clients in the financial services industry. Our study also has the advantage of having a blend of company profiles to add depth to the investigation. The study looks at a mix of banks and insurance firms, service providers and client firms, large and small firms, within an industry but across various countries and across public and private sectors. Firms 2, 3, 6, 12,13 , and 14 indicated that the SOA infrastructure deployment and management characteristics were comparable across countries since the business processes were identical. Contextual variations were limited to business rules catering to local regulations. The profiles of the people interviewed vary from the Head of Corporate Strategy to the Technical Architect, providing a rounded perspective of the implementation of SOA. The analysis also includes firms which ranged from those that considered their attempts at SOA unsuccessful to others that had achieved tangible business benefits from their SOA implementation. The interview data was thematically coded to glean what challenges the firms faced in the process of implementing SOA, and our findings were fairly consistent across the firms interviewed. 
Studies of the practical business impacts of SOA are crucial as the number of SOA implementations grows, and are required for a better critical understanding of this popular architectural concept that is being rapidly adopted by industry organizations. These studies could well provide frameworks, guidelines, and best practices for the effective adoption of SOA as an enterprise strategy, and more importantly what challenges to expect in trying implement these practices.

The business opportunity created by SOA revolves around the reorganization of enterprise information resources as independent, reusable services [27], moving away from viewing corporations as a building block of processes, and re-inventing the corporation to be more a collection of services focused on comparative advantage [11, 22]. The automation of these services creates a new kind of business model, facilitating an integrated process across the enterprise ecosystem to include partners, suppliers, and customers [27]. This makes it critical to have commitment across the organization starting at the board level of the firms.

The evolution to the service paradigm is equally a business and IT transformation [27], and the key to effectively deploying SOA across the enterprise, is to recognize that it is an architecture that transcends technologies and could actually be independent of the underlying technologies that implement it [6]. Not many business people, however, are familiar with the term 'SOA', and many firms whose SOA implementations have fallen well short of expectations possibly did not include the business aspects of the move to a service-based deployment [25]. This risk may be mitigated by training both business and systems people to understand this new model, getting the organization aligned along this model, and changing the mindset of the organization to not only work differently but also leverage existing legacy systems.

Even as SOA is now widely recognized as having the potential to improve the responsiveness of both business and IT organizations, it seems that most organizations that are adopting SOA do not fully understand the business potential of SOA, focusing on technical implementation issues instead of the broader business service view [27]. In this context it is imperative to bear in mind the need for skills training, appropriate governance controls while being cognizant of the slowly maturing technology environment to support the migration to service orientation.

The understanding of how SOA is actually implemented on the ground, the associated implementation issues, the true business value realized, and best practices learned are all areas in which the academic and practitioner literature could be enhanced. In investigating the issues impacting a services implementation, this study

(i) fills a crucial knowledge gap because there is little empirical evidence of the practical use of SOA across the enterprise,

(ii) provides direction for future research, and

(iii) provides a set of guidelines to help practitioners implement SOA successfully across the enterprise.

The findings of this study are part of a larger research effort to leverage the data from the fifteen firms to understand how the enterprise SOA strategy can be aligned with the organizational strategy. The next phase in this research effort involves a continued analysis of the data to develop a framework for SOA implementations. 


\section{Acknowledgements}

The generous scholarship provided by the DEST-funded project ADAGE at UNSW is gratefully acknowledged.

\section{References}

[1] Baskerville, R., et al.: Extensible Architectures: The Strategic Value of Service-Oriented Architecture in Banking. In: Thirteenth European Conference on Information Systems, Regensburg, Germany (2005)

[2] Beidleman, C., Ray, M.: The agility revolution. In: Cortada, J.W., Woods, J.A. (eds.) The Quality Yearbook 1998 (1998)

[3] Benbasat, I., Goldstein, D.K., Mead, M.: The Case Research Strategy in Studies of Information Systems. MIS Quarterly 11(3), 369-386 (1987)

[4] Bieberstein, N., et al.: Impact of service-oriented architecture on enterprise systems, organizational structures, and individuals. IBM Systems Journal 44(4), 691-708 (2005)

[5] Broadbent, M., Weill, P.: Improving business and information strategy alignment: learning from the banking industry. IBM Systems Journal 32(1), 162-179 (1993)

[6] Channabasavaiah, K., Holley, K., Tuggle, E.M.J.: Migrating to a service-oriented architecture. In: On demand operating environment solutions, IBM (2004)

[7] Ciganek, A.P., Haines, M.N., Haseman, W.: Horizontal and Vertical Factors Influencing the Adoption of Web Services. In: Proceedings of the 39th Annual Hawaii International Conference on System Sciences HICSS 2006, p. 6 (2006)

[8] Ciganek, A.P., Haines, M.N., Haseman, W.D.: Challenges of Adopting Web Services: Experiences from the Financial Industry. In: Proceedings of the 38th Hawaii International Conference on System Sciences (2005)

[9] Erlanger, L.: Making SOA Work. In: InfoWorld, pp. 45-52 (2005)

[10] Fricko, A.: SOAs Require Culture Change and Service Reuse. In: Business Communications Review, pp. 58-64 (2006)

[11] Hagel, J.I., Brown, J.S.: Your Next IT Strategy. Harvard Business Review, 105-113 (2001)

[12] Henningsson, S., Svensson, C., Vallen, L.: Mastering the integration chaos following frequent M\&As: IS Integration with SOA Technology. In: Hawaii International Conference on System Sciences 2007, IEEE Computer Society, Big Island (2007)

[13] Jarvenpaa, S.L., Ives, B.: Information technology and corporate strategy: a view from the top. Information Systems Research 1(4), 351-376 (1990)

[14] Lai, V.S., Guynes, J.L.: An assessment of the influence of organizational characteristics on information technology adoption decision: a discriminative approach. IEEE Transactions on Engineering Management 44(2), 146-157 (1997)

[15] Leavitt, N.: Are Web Services Finally Ready to Deliver? In: Computer, pp. 14-16 (2004)

[16] Legner, C., Heutschi, R.: SOA Adoption in Practice-Findings from Early SOA Implementations. In: Österle, H., Schelp, J., Winter, R. (eds.) Proceedings of the 15th European Conference on Information Systems, St. Gallen, Switzerland, pp. 1643-1654 (2007)

[17] Luthria, H., Rabhi, F., Briers, M.: Investigating the Potential of Service Oriented Architectures to Realize Dynamic Capabilities. In: Asia-Pacific Service Computing Conference, The 2nd IEEE (APSCC 2007). IEEE Computer Society, Tsukuba (2007) 
[18] Luthria, H., Rabhi, F.A.: Service Oriented Computing in Practice - An Agenda for Research into the Factors Influencing the Organizational Adoption of Service Oriented Architectures. Journal of Theoretical and Applied Electronic Commerce Research (2008)

[19] Margaria, T., Steffen, B.: Service Engineering: Linking Business and IT. In: Computer (IEEE), p. 45 (2006)

[20] McFarlan, F.W.: Information technology changes the way you compete. Harvard Business Review 62(3), 98-103 (1984)

[21] Mukhi, N.K., Konuru, R., Curbera, F.: Cooperative Middleware Specialization for Service Oriented Architectures. In: International World Wide Web Conference. ACM, New York (2004)

[22] Murray, W.: Implications of SOA on business strategy and organizational design. The SOA Magazine volume (2007)

[23] Papazoglou, M.P., et al.: Service Oriented Computing Research Roadmap. In: Dagstuhl Seminar (2006)

[24] Quocirca SOA: Substance or Hype? Quocirca Ltd. (2005)

[25] Ricadela, A.: The Dark Side of SOA. In: Information Week, pp. 54-58 (2006)

[26] Saunders, S., et al.: The software quality challenges of service oriented architectures in ecommerce. Software Quality Journal 14(1), 65-75 (2006)

[27] Sprott, D.: Service-Oriented Architecture: An Introduction for Managers. CBDI Journal (2004)

[28] Stantchev, V., Malek, M.: Architectural translucency in service-oriented architectures. IEE Proceedings - Software 153(1), 31-37 (2006)

[29] Tsai, W.T.: Service-Oriented System Engineering: A New Paradigm. In: IEEE Workshop on Service-Oriented System Engineering (SOSE 2005). IEEE, Los Alamitos (2005)

[30] Yoon, T., Carter, P.: Investigating the Antecedents and benefits of SOA Implementation: A Multi-Case Study Approach. In: Americas Conference on Information Systems (AMCIS). AIS Electronic Library, Colorado (2007) 